\title{
Kompatibilität des türkischen und europäischen Wirtschaftsrechts
}

\author{
Der neue türkische HGB-Entwurf und benachbarte Rechtsgebiete \\ Hrsg. v. Yesim M. Atamer u. Klaus J. Hopt
}

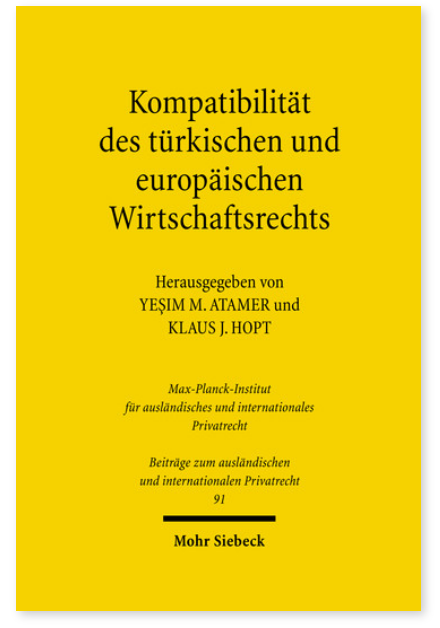

2009. XXVII, 335 Seiten. BtrIPR 91

ISBN 978-3-16-151084-7 DOI 10.1628/978-3-16-151084-7 eBook PDF $94,00 €$

ISBN 978-3-16-150037-4

Leinen $94,00 €$
Die Autoren der hier gesammelten Beiträge vergleichen das türkische und europäische Wirtschaftsrecht in den Bereichen Handels- und Gesellschaftsrecht, Transport-, Seehandels-, Versicherungs-, Kapitalmarkt-, Verbraucher-, Wettbewerbs- und Urheberrecht. Die ersten vier dieser Bereiche sind im türkischen Handelsgesetzbuch geregelt, welches z. Zt. in Neufassung dem Parlament vorliegt und voraussichtlich 2009 in Kraft treten wird. Die Inspirationsquellen für die Reformen waren das EURecht, internationale Abkommen und international anerkannte Normen von Handels- und anderen Organisationen. Viele der türkischen Autoren dieses Buches waren an der Abfassung des Entwurfes direkt beteiligt. Folglich beinhalten die Aufsätze auch wichtige Hintergrundinformationen. Das Kapitalmarktrecht ist in der Türkei seit 1981 durch Gesetz geregelt und seitdem im Hinblick auf die europarechtlichen Vorgaben maßgeblich geändert worden. Dies gilt auch für das Wettbewerbs- und das Verbraucherrecht, da die beiden einschlägigen Gesetze mit Blick auf die Gründung der Zollunion zwischen der Türkei und der EU Ende 1994 bzw. 1995 erlassen wurden und hauptsächlich der Umsetzung der relevanten Verordnungen und Richtlinien dienten. Auch das Urheberrechtsgesetz von 1952 wurde seit 1995 entsprechenden Revisionen unterzogen. Insgesamt lässt sich der Schluss ziehen, dass das türkische Wirtschaftsrecht mit dem Erlass des neuen HGB und den geplanten letzten Änderungen in den Nebengesetzen ein hohes Niveau der Anpassung an das EU-Recht haben wird.

Inhaltsübersicht

\section{Handels- und Gesellschaftsrecht}

Ünal Tekinalp: Leitlinien der türkischen Handelsrechtsreform - Klaus J. Hopt: Reformprobleme im Handels-, Gesellschaftsund Abschlussprüferrecht. Bemerkungen zur türkischen Handelsrechtsreform 2008

\section{Kapitalmarktrecht}

Veliye Yanli: Kapitalmarktrechtliche Publizitätspflichten von Aktiengesellschaften in der Türkei - Holger Fleischer: Kapitalmarktrechtliche Publizitätspflichten im Gemeinschaftsrecht

III. Transportrecht

Arslan Kaya:Analysis of the Provisions regarding Carriage of Goods by Road in the Turkish Commercial Code and the Draft Turkish Commercial Code - Krijn F. Haak: Das neue türkische Transportrecht im Lichte internationaler Entwicklungen IV. Seehandelsrecht

Kerim Atamer:Reform des Seehandelsrechts im Entwurf des türkischen Handelsgesetzbuchs - Beate Czerwenka: Reform des Seehandelsrechts - ein deutsch-türkischer Vergleich

V. Versicherungsrecht

Samim Ünan: Some Aspects of the New Turkish Legislative Work Related to Private Insurance - Christian Armbrüster: Aktuelle Entwicklungen des türkischen Versicherungsaufsichts- und -vertragsrechts im Vergleich zum deutschen und europäischen Recht

VI. Verbraucherrecht

Yesim M. Atamer, Hans W. Micklitz: Türkisches Verbraucherrecht im Lichte des EG-Rechts

VII. Wettbewerbsrecht

Osman B. Gürzumar: Zehn Jahre türkisches Wettbewerbsrecht. Ein zusammenfassendes Bild im Lichte des europarechtlichen Harmonisierungsprozesses - Jürgen Basedow: Zehn Jahre türkisches Wettbewerbsrecht. Ein europäischer Kommentar VIII. Urheberrecht

Gül Okutan Nilsson: Harmonisation of Turkish Copyright Law with EU Law - Reto M. Hilty: Türkisches Urheberrecht und Europäischer Acquis Communautaire

Yesim M. Atamer ist Associate Professor an der Istanbul Bilgi University, Faculty of Law.

Klaus J. Hopt ist Direktor emeritus des Max-Planck-Instituts für ausländisches und internationales Privatrecht in Hamburg und Professor emeritus an der Universität Hamburg; vormals Richter am OLG Stuttgart.

Jetzt bestellen:

https://mohrsiebeck.com/buch/kompatibilitaet-des-tuerkischen-und-europaeischen-wirtschaftsrechts-9783161510847? no_cache=1

order@mohrsiebeck.com

Telefon: +49 (0)7071-923-17

Telefax: $+49(0) 7071-51104$ 